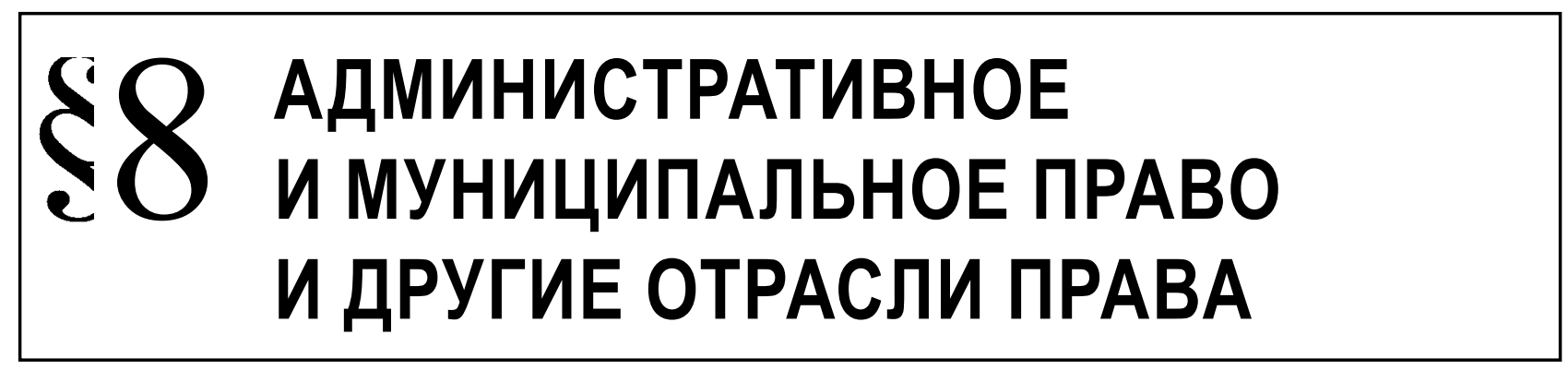

\title{
ИНФОРМАЦИОННОЕ ОБЕСПЕЧЕНИЕ ПРОТИВОДЕЙСТВИЯ ПРЕСТУПЛЕНИЯМ, СВЯЗАННЫМ С ТОРГОВЛЕЙ ЛЮДЬМИ
}

Аннотация. Представленная статья посвящена исследованию понятия информации и информацион ного обеспечения противодействия преступлениям, связанных с торговле людьми. Автор приходит к выводу:Информация в органах внутренних дел - это собранные, обработанные и проанализированные статистические, оперативные и иные сведения, характеризующие оперативную обстановку, снижающие уровень неопределенности и оцененные как полезные для принятия соответствующего решения, способствующего выполнению конкретных задач.2. Информационное обеспечение противодействия торговле людьми это специфический вид деятельности, направленный на создание системы источников информации, конкретизацию сферы ее применения, времени, направления и способа оценки ее относимости, достоверности, достаточности и своевременности с целью дальнейшего ее использования для эффективного решения задач по выявлению, предупреждению, раскрытию преступлений, связанных с торговлей людьми . Диалектический метод научного познания объективной действительности, научный анализ, изучение документов, формально логический и социологический методы познания Изучение результатов деятельности оперативных подразделений органов внутренних дел позволяет отнести к числу основных причин роста преступности в целом и преступлений, связанных с торговлей людьми, в частности, недостатки информационного обеспечения. Автор предлагает к рассмотрению свое видение понятия информации и информационного обеспечения с отражением специфики противодействия преступлениям, связанным с торговлей людьми.

Ключевые слова: информация, информационное обеспечение, противодействие торговле людьми, оперативно-разыскная деятельность, органы внутренних дел, система источников информации, требования к информации, оценка информации, оперативная обстановка, оперативная информация.

Abstract. The article studies the concept of information, and information support for anti-trafficking in persons. The author concludes that:1) Information in the sphere of domestic affairs includes the collected, processed, and analyzed statistical, operational, and other data characterizing operational environment, increasing the level of uncertainty, and considered to be useful for making a decision promoting the implementation of particular tasks.2) Information support for anti-trafficking in persons is a specific form of activity aimed at creating the system of sources of information, specifying its field of application, time period, direction, and method of evaluating its relevance, validity, sufficiency, and timeliness, in order to use it for the effective solution of the tasks of revelation, prevention, and detection of crimes connected with trafficking in persons. The author applies the dialectical method of cognition, the scientific analysis, the analysis of documents, the technical and sociological methods. The author concludes that the drawbacks of information support can be considered among the reasons for increase in crime in general and trafficking in persons in particular. The author proposes her own understanding of the concept of information and information support, which reflects the specificity of anti-trafficking in persons.

Key words: operational environment, information, evaluation of information, information support, anti-trafficking in persons, investigative activities, internal affairs bodies, System of sources of information, information requirements, operative information.

$\Pi$ реступность последнего десятилетия характеризуется не только увеличением общего количества совершаемых преступлений, но и изменением ее качественного состава. Так, особую тревогу вызывает возрождение тех видов преступлений, которые, казалось бы, навсегда побеж- дены обществом. Как свидетельствует статистика, с момента включения в 2004 году в состав Уголовного кодекса РФ [13]. ст.. $127^{1}$ «торговля людьми» и ст. $127^{2}$ «и использование рабского труда» количество возбуждаемых уголовных дел по данным составам неуклонно растет. 


\section{Административное и муниципальное право 3 (99) • 2016}

Изучение результатов деятельности оперативных подразделений органов внутренних дел (далее ОВД) позволяет отнести к числу основных причин роста преступности в целом и преступлений, связанных с торговлей людьми, в частности, недостатки информационного обеспечения. Ценность этого института оперативно-разыскной деятельности соотносится с лексическим значением глагола «обеспечить», т.е. снабдить чем-то в нужном количестве, сделать вполне возможным реальным, выполнимым[6]. В связи с этим бесспорен вывод С.С. Овчинского, который считал информационное обеспечение сердцевиной оперативно-разыскной деятельности [10].

В ст. 10 Федерального закона «Об оперативнорозыскной деятельности» (далее ФЗ Об ОРД) [14], законодатель не раскрывает понятия информационного обеспечения, но наделяет органы, осуществляющие оперативно-розыскную деятельность, возможностью для решения задач, возложенных на них настоящим Федеральным законом, создавать и использовать информационные системы, а также заводить дела оперативного учета. Таким образом, подразумевая под информационным обеспечением оперативно-разыскной деятельности, процесс по формированию и использованию информационных систем, т.к., в широком понимании, ведение дел оперативного учета направлено на сбор оперативно-значимой информации, которая в идеале может быть использована в качестве доказательства по уголовному делу.

Следует отметить, что современная теория оперативно-разыскной деятельности активно реагировала на запросы практики, связанные с информационным обеспечением деятельности органов внутренних дел по раскрытию преступлений. Данное направление противодействия преступности относится к числу ключевых проблем современной науки, что отразилось в научной полемике по данному вопросу.

С одной стороны, информационное обеспечение деятельности ОВД противодействия преступности, рассматривается как система, состоящая из нескольких элементов или подсистем: содержательной (оперативно-разыскная информация), организационной (способы получения) и технической (технические средства, гарантирующие их выполнение) [2]. Подобной позиции придерживается и В.И. Басков [2].

В.Г. Афанасьев рассматривает информационное обеспечение как одно из средств переработки информации [1].

Другие авторы понимают под информационным обеспечением противодействия преступности некий процесс снабжения оперативных подразделений оперативно-разыскной информацией
[4].Вместе с тем за пределами понятия оперативно-разыскного обеспечения остаются действия по обработке, накоплению и использованию полученной информации.

Нельзя не обратить внимание, что формирование понятия об информационном обеспечении противодействия торговле людьми неразрывно связано с понятием «информация». К.К. Вальпух отмечает, что нечеткое определение термина «информация» ведет к неоднозначному пониманию как его самого, так и производных от него[3]. Согласно ст. 2 Федерального закона «Об информации, информационных технологиях и о защите информации», информация- это сведения (сообщения, данные) независимо от формы их представления (далее ФЗ Об информации) [15].. Данное определение формирует общее понимание информации, но не отражает ни сущности, ни функции, ни практической значимости информации, а также механизмов ее распространения и возникновения.

Для отражения специфики информации применительно к конкретной области познания и практической деятельности, в частности, противодействия торговле людьми, необходимо выделить и проанализировать ее особенности.

Так, авторы пособия «Научная организация управления органами внутренних дел» [8] предлагают свое видение информации как конечный этап трансформации полученных данных. По их мнению, данные, а именно, полученные с помощью любых носителей факты, события (не зависимо от того получены они адресатом или интересуют кого-либо), соотнесенные с определенной областью их использования, будут представлять знания. А знания, служащие решению определенной задачи, уже являются информацией. Информация должна быть конкретизирована, должным образом организована, отнесена к конкретной ситуации и конкретному виду отношений, квалифицированна по видам и, применена для решения конкретных задач. Не вызывает сомнение, что оперативно-розыскная деятельность по противодействию торговле людьми обладает определенной спецификой, вызванной, как отмечают респонденты, трудностью идентификации жертв - 70\% опрошенных, вовлеченностью пострадавших от торговли людьми в преступленную деятельность - 48 \% , негативным отношением населения к лицам, оказывающим сексуальные услуги и вовлеченным в попрошайничество (одни из самых распространенных форм эксплуатации) - 59 \%, слабым взаимодействием между подразделениями органов внутренних дел 32 \% (интервьюированным предлагались на выбор несколько вариантов ответов). Отсюда особую актуальность приобретает необходимость опреде- 
ления источников получения информации и выбор наиболее значимых ее признаков.

В то же время на вопрос: «В какой информации в первую очередь у Вас ощущается наибольшая потребность?», 49\% ответили - причастность противоправной деятельности; 42 \%- признаки лиц, вовлеченных или участвующих в осуществлении торговли людьми; 36 \% - наличие судимости; 29\% - наличие связей в преступной среде; $26 \%$ - биографические данные; 26 \% - данные о местонахождении лица в определенный период; 13\% - способности, наклонности; $12 \%$ - участие в совершении противоправных действий иностранцев на территории своего государства; $11 \%$ - состояние здоровья; $11 \%$ - возможность выезжать за пределы Российской Федерации; 9 \% - факт обращения в консульства и представительства иностранных государств; 9 \%- - материальное положение лица, 8 $\%$ - факт обращения в туристические агентства; 4 \%- изменение социального статуса.

В качестве наиболее используемых источников для получения информации респонденты выделяют 41 \% - конфиденты; 34\% - учеты органов внутренних дел, 30\% - учеты иных государственных органов, 29\% - учеты негосударственных органов, $15 \%$ - интернет - ресурсы; $13 \%$-средства массовой информации; $1 \%$ - консульства и представительства иностранных государств.

Вопрос «Какие задачи предполагаете решить с помощью информационного обеспечения?» вызвал следующие ответы: 59\% - снижение уровня неопределенности; 44 \% - выбор средств и тактики оперативно-разыскной деятельности при решении соответствующих задач; 43 \% - изучение оперативной обстановки; 31\% - информирование заинтересованных подразделений ОВД; 24 \%- выбор тактики по защите источников информации.

В рамках исследования нами изучались обстоятельства, затрудняющие оценку и анализ полученной информации, необходимой для организации противодействия торговле людьми. Ответы распределились следующим образом: 65\% - отсутствие единого банка данных; 61\% - несогласованность информационных систем органов внутренних дел, вынуждающих обращаться к различным видам учетов; 56\% - формальный подход к проверке конфиденциальной информации, полученной от другого оперативного подразделения, 44\% отсутствие сведений о противоправной деятельности иностранных на территории своего государства, въезжающих в Российскую Федерацию; 31\%необходимость самостоятельно анализировать большой поток информации, которая не содержит явных признаков торговли людьми.

Вышеизложенное свидетельствует о высоком понимании сотрудниками оперативных подразде- лений значения информации для решения задач оперативно-разыскной деятельности, в том числе, по противодействию торговле людьми.

Информация воздействует на все функции, осуществляемые оперативными подразделениями ОВД и решаемые ими задачи. И чем рациональней организовано информационное обеспечение, тем более обоснованно принимаются решения, и осуществляется их реализация.

Следовательно, любой государственный орган выполняет свои функции средствами и методами, присущими управлению, как специфическому виду деятельности посредством реализации общих функций управления, в том числе и информационного обеспечения[9].

Учитывая вышеизложенное, полагаем, что информация в органах внутренних дел - это собранные, обработанные и проанализированные статистические, оперативные и иные сведения, характеризующие оперативную обстановку, снижающие уровень неопределенности и оцененные как полезные для принятия соответствующего решения, способствующего выполнению конкретных задач.

Информация, используемая в органах внутренних дел, в том числе и для противодействия торговле людьми, может быть разделена на два потока: свободно распространяемый и распространяемый в условиях конфиденциальности. Под распространением информации законодатель в понимает действия, направленные на получение информации неопределенным кругом лиц, или передачу информации неопределенному кругу лиц (ст. 2 ФЗ Об Информации).

Без решения вопроса организации внутреннего и внешнего потоков информации невозможно повысить оперативность принятия решения и, следовательно, успешно выполнить задачи, стоящие перед оперативным подразделением. Здесь нельзя не согласиться с мнением Т. А. Ткачук, что информационные ресурсы, не согласованные по форме представления данных и способам их учета, рассредоточенные в различных информационных массивах, не отвечают современным требованиям розыскной деятельности и нуждаются в совершенствовании через централизацию, объединение в общую регистрационную систему (включающую в себя, помимо прочих, информационно-поисковую систему регистрации граждан) в рамках создания единого информационного пространства России [12].

Возникает потребность в формировании банка информации стратегического и тактического назначения, который включил бы в себя сведения о лицах, замышляющих, подготавливающих или совершающих преступления, связанные с торговлей людьми, допускающих отклонения от установленных норм поведения в виде совершения 
административных правонарушений, указывающих на причастность к торговле людьми; других категориях лиц и материальных объектах (лицах, которые могут выступать в качестве конфидентов, и других лиц, которые могут располагать информацией о криминальных событиях и причастных к ним гражданах; о возможных местах укрывательства скрывшихся преступников, о способах совершения исследуемого преступления, о способах ограничения свободы жертв торговли людьми, о способах криминального противодействия оперативным подразделениям, о признаках эксплуатации жертв, о признаках, позволяющих идентифицировать жертв; о признаках, указывающих на виктимное поведение); об обстоятельствах, способствующих совершению преступлений, а также имеющих существенное значение для решения задач, возникающих в процессе оперативно-разыскной деятельности.

Соответственно, этот этап должен быть направлен, в первую очередь на то, чтобы поступающие в эти подразделения из различных источников сведения были изучены на предмет ценности и возможности их дальнейшего использования в решении задач ОРД.

На последующих этапах, путем анализа полученных сведений вырабатываются конкретные, управленческие решения по использованию этой информации в виде результатов оперативно-разыскной работы для подготовки и осущест- вления оперативно-разыскных мероприятий, следственных и судебных действий, проведения последующих оперативно-разыскных мероприятий, согласно ст. 11 Федерального Закона «Об оперативно-розыскной деятельности». Таким образом, являясь элементом научного управления подразделений уголовного розыска, правильная организация их информационного обеспечения способствует эффективному решению задач по противодействию торговле людьми.

Обобщая вышеизложенное, отметим:

1. Информация в органах внутренних дел - это собранные, обработанные и проанализированные статистические, оперативные и иные сведения, характеризующие оперативную обстановку, снижающие уровень неопределенности и оцененные как полезные для принятия соответствующего решения, способствующего выполнению конкретных задач.

2. Информационное обеспечение противодействия торговле людьми это специфический вид деятельности, направленный на создание системы источников информации, конкретизацию сферы ее применения, времени, направления и способа оценки ее относимости, достоверности, достаточности и своевременности с целью дальнейшего ее использования для эффективного решения задач по выявлению, предупреждению, раскрытию преступлений, связанных с торговлей людьми.

\section{Библиография:}

1. Афанасьев В.Г. Человек в управлении обществом. М., 1975. С. 136.

2. Басков В.И. Оперативно-розыскная деятельность. М., 1997. С. 83-86.

3. Вальпух К.К. Информационная теория стоимости и законы неравновесной экономики. М., 2001. С. 47.

4. Гальцов В.С. Сущность и содержание процесса информационного обеспечения деятельности оперативных аппаратов ОВД // Теоретические и практические проблемы оперативно-розыскной деятельности: Сб. ст. Калининград, 1990. С. 120.

5. Криминология: учебник для вузов / Под ред. В.Д. Малкова, 2011. С. 22.

6. Лопатин В.В., Лопатина Л.Е. Малый толковый словарь русского языка М., 1990. С. 306.

7. Лукашов В.А. Организация и методика информационно-аналитической работы в сфере оперативно-розыскной деятельности органов внутренних дел: Лекция. Омск, 1983. С. 3.

8. Научная организация управления органами внутренних дел: Уч. пособие / Под ред. Г.Г. Зуйкова. М., 1984. С. 13.

9. Общая теория управления: Материалы к лекциям / Под общ. ред. Пищулина Н.П. М., 1993. С. 61-62.

10. Овчинский С.С. Оперативно-розыскная информация / Под ред. А.С. Овчинского, В.С. Овчинского. М., 2000. С. 3.

11. Титов Е.М. Понятие и сущность системы информационного обеспечения деятельности органов внутренних дел // Проблемы информационного обеспечения деятельности органов внутренних дел. М., 1981. С. 11.

12. Ткачук Т.А. Научно-техническое обеспечение розыскной дельности в уголовном процессе России: автореферат д. ю. н., Владимир, 2011. С. 11.

13. Уголовный кодекс Российской Федерации от 13.06.1996 № 63-ФЗ (ред. от 05.04.2013 г.) // Электронный ресурс Консультант плюс.

14. Федеральный закон от 12 августа 1995 г. № 144-Ф3 «Об оперативно-розыскной деятельности»// СЗРФ, 14.08.1995, №33, ст. 3349; СЗ РФ 08.04.2013, № 14. Ст. 1661.

15. Федеральный закон от 27 июля 2006 г. «Об информации, информатизации и о защите информации» // СЗ РФ. 2006. № 31(ч. 1). Ст. 3448.

\section{References (transliterated):}

1. Afanas'ev V.G. Chelovek v upravlenii obshchestvom. M., 1975. S. 136. 
2. Baskov V.I. Operativno-rozysknaya deyatel'nost'. M., 1997. S. 83-86.

3. Val'pukh K.K. Informatsionnaya teoriya stoimosti i zakony neravnovesnoi ekonomiki. M., 2001. S. 47.

4. Gal'tsov V.S. Sushchnost' i soderzhanie protsessa informatsionnogo obespecheniya deyatel'nosti operativnykh apparatov OVD // Teoreticheskie i prakticheskie problemy operativno-rozysknoi deyatel'nosti: Sb. st. Kaliningrad, 1990. S. 120.

5. Kriminologiya: uchebnik dlya vuzov / Pod red. V.D. Malkova, 2011. S. 22.

6. Lopatin V.V., Lopatina L.E. Malyi tolkovyi slovar' russkogo yazyka M., 1990. S. 306.

7. Lukashov V.A. Organizatsiya i metodika informatsionno-analiticheskoi raboty v sfere operativno-rozysknoi deyatel'nosti organov vnutrennikh del: Lektsiya. Omsk, 1983. S. 3.

8. Nauchnaya organizatsiya upravleniya organami vnutrennikh del: Uch. posobie / Pod red. G.G. Zuikova. M., 1984. S. 13.

9. Obshchaya teoriya upravleniya: Materialy k lektsiyam / Pod obshch. red. Pishchulina N.P. M., 1993. S. 61-62.

10. Ovchinskii S.S. Operativno-rozysknaya informatsiya / Pod red. A.S. Ovchinskogo, V.S. Ovchinskogo. M., 2000. S. 3.

11. Titov E.M. Ponyatie i sushchnost' sistemy informatsionnogo obespecheniya deyatel'nosti organov vnutrennikh del // Problemy informatsionnogo obespecheniya deyatel'nosti organov vnutrennikh del. M., 1981. S. 11.

12. Tkachuk T.A. Nauchno-tekhnicheskoe obespechenie rozysknoi del'nosti v ugolovnom protsesse Rossii: avtoreferat d. yu. n., Vladimir, 2011. S. 11.

13. Ugolovnyi kodeks Rossiiskoi Federatsii ot 13.06.1996 № 63-FZ (red. ot 05.04.2013 g.) // Elektronnyi resurs Konsul'tant plyus.

14. Federal'nyi zakon ot 12 avgusta 1995 g. № 144-FZ «Ob operativno-rozysknoi deyatel'nosti»// SZRF, 14.08.1995, №33, st. 3349; SZ RF 08.04.2013, № 14. St. 1661.

15. Federal'nyi zakon ot 27 iyulya 2006 g. «Ob informatsii, informatizatsii i o zashchite informatsii» // SZ RF. 2006. № 31(ch. 1). St. 3448. 